\title{
Hepatocellular carcinoma in adult thalassemia patients: an expert opinion based on current evidence
}

\author{
Alessandra Mangia ${ }^{1 *}$ D, Davide Bellini ${ }^{2}$, Umberto Cillo ${ }^{3}$, Andrea Laghi ${ }^{4}$, Giuseppe Pelle ${ }^{5}$, Vanna Maria Valori ${ }^{6}$ and \\ Eugenio Caturelli
}

\begin{abstract}
Beta-thalassemia represents a heterogeneous group of haemoglobin inherited disorders, among the most common genetic diseases in the world, frequent in the Mediterranean basin. As beta-thalassemia patients' survival has increased over time, previously unknown complications are observed with increasing frequency. Among them, an increased risk of hepatocellular carcinoma (HCC) has been registered. Our aim is to reduce inequalities in diagnosis and treatment and to offer patients univocal recommendations in any institution.

The members of the panel - gastroenterologists, radiologists, surgeons and oncologists -were selected on the basis of their publication records and expertise. Thirteen clinical questions, derived from clinical needs, and an integration of all the committee members' suggestions, were formulated. Modified Delphi approach involving a detailed literature review and the collective judgement of experts, was applied to this work.

Thirteen statements were derived from expert opinions' based on the current literature, on recently developed reviews and on technological advancements. Each statement is discussed in a short paragraph reporting the current key evidence. As this is an emerging issue, the number of papers on HCC in beta-thalassemia patients is limited and based on anecdotal cases rather than on randomized controlled studies. Therefore, the panel has discussed, step by step, the possible differences between beta-thalassemia and non beta-thalassemia patients. Despite the paucity of the literature, practical and concise statements were generated.

This paper offers a practical guide organized by statements describing how to manage HCC in patients with betathalassemia.
\end{abstract}

Keywords: Beta-thalassemia, Hepatocellular carcinoma, HCC, Iron overload, HCV, HBV, RMI,TACE, TARE, OLT

\section{Background}

Beta-thalassemia represents a heterogeneous group of inherited disorders in the synthesis of haemoglobin. It concerns homozygous and double heterozygous patients with deletions in $\beta$ and $\delta \beta$ chains genes or, in general, genetic defects of $\beta$ chains in general. Beta-thalassemia is among the most common genetic diseases in the

\footnotetext{
* Correspondence: a.mangia@tin.it

'Liver Unit, Department of Medical Sciences, Fondazione IRCCS "Casa Sollievo della Sofferenza", San Giovanni Rotondo, Italy

Full list of author information is available at the end of the article
}

world, frequent in the Mediterranean basin. Betathalassemia patients present reduced or absent synthesis of beta globin's chains, consequent anemia due to erithroblasts destruction within the bone marrow, and red cells destruction in peripheral blood, ineffective erythropoiesis and iron overload. As beta-thalassemia patients' survival has increased over time [1-3] new previously unknown complications are observed, including an increased risk of hepatocellular carcinoma (HCC).

In addition to the factors reported in non betathalassemia patients, the risk of HCC development in

(c) The Author(s). 2020 Open Access This article is licensed under a Creative Commons Attribution 4.0 International License, which permits use, sharing, adaptation, distribution and reproduction in any medium or format, as long as you give appropriate credit to the original author(s) and the source, provide a link to the Creative Commons licence, and indicate if changes were made. The images or other third party material in this article are included in the article's Creative Commons licence, unless indicated otherwise in a credit line to the material. If material is not included in the article's Creative Commons licence and your intended use is not permitted by statutory regulation or exceeds the permitted use, you will need to obtain permission directly from the copyright holder. To view a copy of this licence, visit http://creativecommons.org/licenses/by/4.0/ The Creative Commons Public Domain Dedication waiver (http://creativecommons.org/publicdomain/zero/1.0/) applies to the data made available in this article, unless otherwise stated in a credit line to the data. 
beta-thalassemia is linked to several factors: the high risk of infections transmitted by blood transfusions, responsible of chronic liver diseases as HCV and, at lower impact, HBV; the debatable risk that blood transfusions inhibit immune-surveillance against cancer [4] and, most importantly, the peculiar risk, compared to other transfusion-dependent blood disorders, that a progressive iron overload favors neoplastic liver transformation.

In patients with transfusion dependent (TD) betathalassemia major (TM), iron overload is not only a consequence of blood transfusions, but also the direct effect of the increased iron absorption. By contrast, in patients with thalassemia intermedia (TI) -defined as a clinical variant of thalassemia characterized by a thalassemia phenotype of mild-moderate degree of severity- able to maintain $\mathrm{Hb}$ levels of $7 \mathrm{~g} / \mathrm{dl}$ without regular blood transfusion (NTD), iron overload, in addition to the increased absorption, is due to ineffective erythropoiesis. Moreover, iron chelation, regular in TD beta-thalassemia, is less codified in NTD.

Accumulating in the hepatocytes, iron plays a direct role in cancer development $[5,6]$. Excess of iron not carried by transferrin as in normal individuals, but detected in forms referred as labile iron, promotes $\mathrm{O}$ reactive formation and seriously damages lipid membranes, intracellular proteins and DNA [7]. Consequences are mutations in some "tumor suppressor genes" including p53 and in "DNA repair" genes.

In addition to these mechanisms leading to neoplastic transformation, iron overload favors fibrosis progression by stellate cells activation and by a pro-fibrogenic effect of lipid peroxidation and is also associated with immunologic changes responsible of macrophage altered function [8].

Iron overload and HCV infection represent independent risk factors for liver fibrosis progression [9] and their coexistence enormously increases the risk of cirrhosis. Thanks to the blood donors screening [10] and to the possibility to cure $\mathrm{HCV}$ infection using direct acting antivirals (DAA), able to induce a sustained virological response at week 12 of follow-up (SVR12) of 98\% in beta-thalassemia patients with $\mathrm{HCV}$ infection [11] -but also safe and easy to manage-, the relative risk of HCC is expected to significantly decline over time. While risk of HCV-related HCC will diminish, the impact of iron overload in cirrhosis development will persist unless an efficient chelation program is not undertaken. Remarkably, HCC was diagnosed even in TI patients NTD [1], currently representing in Italy about $1 / 3$ of the total thalassemia patients.

Despite the accumulation of knowledge in this field, no practical guidelines on HCC in beta-thalassemia have been published so far. Consequently, for betathalassemia patients, the risk of not receiving the best treatment, because of limited local expertise, exists. The aim of this work is to reduce inequalities in diagnosis and treatment of HCC and to offer beta-thalassemia patients the best shared care in any single institution.

\section{Main body \\ Are HCC prevalence and incidence in beta-thalassemia patients higher than in non beta-thalassemia patients?}

Incidence and prevalence of HCC do not differ between beta-thalassemia and non beta-thalassemia patients.

According to the 2019 AIOM report, 33.000 patients had HCC diagnosis in Italy between 2013 and 2018 [12]. Among beta-thalassemia patients, HCC prevalence ranged from $2.3 \%$ in Greece to $1 \%$ in Italy [1, 13]. Another study reported that HCC prevalence in male patients with beta-thalassemia is 6 times higher than in non beta-thalassemia subjects [14].

HCC incidence, standardized by age in non betathalassemia patients can be estimated at 10.9/100.000 P/ $\mathrm{Y}$ for male and 3.1/100.000 $\mathrm{P} / \mathrm{Y}$ for female [13]. Incidence of $1.02 / 100.000 \mathrm{P} / \mathrm{Y}$ was estimated in the Italian Thalassemia Registry including 5855 patients [1]. Annual incidence of $2 \%$ was reported in a cohort of $108 \mathrm{TM}$ or TI under US surveillance (C) [15].

\section{Who are beta-thalassemia patients at risk of HCC who need surveillance?}

In addition to the standard surveillance criteria in patients without betathalassemia, patients to be surveilled are beta-thalassemia patients (either TM or TI) with:

-chronic hepatitis HBV or HCV, with or without iron overload

-liver cirrhosis of any etiology, with or without iron overload, including subjects in transplantation waiting list

-iron overload, regardless of the presence of cirrhosis

Among patients without beta-thalassemia, HCC occurs more frequently in patients with HCV or HBV hepatitis or alcohol abuse. In Italy, the number of patients with $\mathrm{HCC}$ is increasing, although the etiologic factors are changing. Within the ITALICA cohort HCC increased from 624 to 1130 over time [16]. A decline in the percentage of HCV related HCC from 51 to $49 \%$, and of HBV related HCC from 3.3 to $2.1 \%$ was reported [17]. Nowadays, HCC related to HCV and HBV infections account for $50 \%$ of liver tumors whereas HCC related to non-viral etiology make up for $32.4 \%$ [18].

In beta-thalassemia patients, $\mathrm{HCV}$ infection with or without iron overload has been the most frequent etiology until recently. In those who received blood transfusions before 1990, HCV infection prevalence was 
proportional to the number of transfused units. In studies published in 2000, HCV Ab resulted positive in $85 \%$ of Italian beta-thalassemia patients [19, 20]. Active HCV infection confirmed by HCV RNA replication has been shown in $50 \%$ of HCVAb positive subjects [21]. Higher rates of anti $\mathrm{HCV}$ positive patients were reported up to 1992 in Greece [22].

Careful donor screening reduced $\mathrm{HCV}$ related transfusion risk to 0.1 per 1.000000 [23, 24]. Therefore, patients with beta-thalassemia, infected before 1990, represent the main group at risk of developing cirrhosis and HCC. As the majority of patients has been treated with $\mathrm{IFN} \pm \mathrm{RBV}$ in the past or with DAA since 2014, the risk of cirrhosis of viral etiology will become less relevant in the future.

\section{$H B V$}

For many years, beta-thalassemia children have been considered at risk of HBV infection. Currently, vaccination programs and blood donor screening have been shown to drastically reduce the incidence of HBV infection in Italy.

Hepatitis B virus integrates in human DNA and is associated with an intrinsic risk of HCC induction. Prevalence of HBV infection in the Mediterranean area ranges from $0.8 \%$ in Turkey [25] to $29 \%$ in Egypt [26]. In the Italian thalassemia registry, an active HBV infection was diagnosed in $5 \%$ of patients with HCC, while a past $\mathrm{HBV}$ infection based on anti $\mathrm{HBcAg}$ positive was observed in $58 \%$ of cases [1].

\section{Iron overload}

Hepatocytes are the main iron storage sites in the body. No biological mechanisms exist for the excretion of excess iron. Iron overload is defined as an increase in total body iron, and liver is the most affected organ. Iron overload in beta-thalassemia occurs when (a) iron storage is insufficient to bear the excess of iron derived from erythrocyte catabolism and increased absorption in TDT; (b) levels of epcidin hormon responsible of increased iron intestinal absorption are low and the amount of iron released in the blood increases leading to an excess of iron liver storage as inTI.

When the level of safe iron sequestration is exceeded, the storage protein ferritin is denatured, releasing large amounts of iron ions into the cytoplasm of the hepatocytes. Iron accumulation in the liver results in hepatocyte damage and dysfunction leading to fibrosis development. Iron overload and $\mathrm{HCV}$ work in synergy in promoting fibrosis progression towards liver cirrhosis [9].

Liver iron overload "per se" may be complicated by malignant transformation in the absence of viral infections [1, 27, 28]. Several main mechanisms of cancerogenesis have been hypothesized [27-30].

\section{Cirrhosis}

Liver cirrhosis is the main risk factor for HCC. In patients without beta-thalassemia, cohort studies demonstrated that mortality in HCC is dependent on the severity of the underlying cirrhosis, the main etiological factors being $\mathrm{HCV}$ and hemochromatosis [31]. Additional risk factors were the presence of an active viral infection, older age, co-morbidities including coinfections, alcohol abuse, obesity, and diabetes.

In beta-thalassemia patients, cirrhosis is reported in $20 \%$ of cases $[9,14,32]$. However, the number of cirrhotic patients with HCC in Italy is unknown. Published data in patients with beta-thalassemia and HCC do not provide details on severity of the underlying liver disease. I.

Does HCC development in beta-thalassemia patients necessarily require the presence of liver cirrhosis?

To present knowledge, HCC development in beta-thalassemia patients does not necessarily require the presence of liver cirrhosis and in the absence of cirrhosis it is more frequently observed inTI.

In non beta-thalassemia patients the prevalence of HCC in non-cirrhotic population is reported at $9.6 \%$, with an upwards trend especially in patients with NAFLD [16].

In a letter published by Restivo Pantalone, only 1 out of 9 cases had cirrhosis [33]. Of an Italian cohort published in 2014 only 4 out of 60 had cirrhosis [1]. Of the $2 \mathrm{HCC}$ beta-thalassemia patients reported by Makaron, none had cirrhosis [34]. Fragatou published 5 HCC cases of whom 2 had cirrhosis [32].

Seven cases with occurrence of HCC in non-cirrhotic livers have been described: two patients with TI (one of them with HCV-positivity); one patient with TM and HCV-positivity; two patients with TI (one of them with HCV-positivity); two patients with TI and negativity both for HBV and HCV [35]. All these cases presented iron overload and although episodic, confirm the possibility that iron overload alone could induce the development of HCC $[1,30]$.

Persistently high LIC (Liver Iron Concentration) values as a consequence of differences in monitoring schedules either in TD or in NTD patients may play a role [36]. 
Is there a residual risk of $\mathrm{HCC}$ in $\mathrm{HCV}$ infected betathalassemia patients who attain SVR12 after antiviral therapy, or in patients with chronic HBV infection controlled by Nucleos(t) ide analogues (NUCs)?

In patients with beta-thalassemia who attain SVR12 after antiviral therapy for HCV or control of HBV on NUCS, a residual risk of HCC is related to the severity of iron overload.

The recent introduction of direct acting antiviral (DAA) against HCV led to extremely high SVR12 [11, 37]. In non beta-thalassemia patients, after SVR12 the risk of HCC although reduced is not zeroed [38, 39] although not different from that after Interferon. The risk is increased by severity of the underlying liver disease and presence of co-morbidities. Not achieving DAA response was associated with increased HCC risk [40]. Chronic HBV infection is safely controlled by NUCs. In non beta-thalassemia patients, the risk of HCC after Tenofovir alafenamide or entecavir is not zeroed. HCC predictors are cirrhosis or severe fibrosis, age and male gender. Patients with NUCs-induced HBsAg seroclearance, on top of complete viral suppression, have a lower risk of $\mathrm{HCC}$ than those only achieving complete viral suppression under prolonged NUCs treatment [41].

In patients with NUCs -induced HBsAg lost, HCC risk is similar to that of patients with spontaneous HBsAg lost and can be estimated around $1 \%$ at 5 years [42].

There are no available data in the setting of betathalassemia patients where the risk may be increased by the presence of iron overload.

Biannual surveillance is required in at risk patients regardless of SVR12 achievement or NUCs induced HBV DNA control.

What is the most accurate test to non-invasively diagnose advanced liver fibrosis in beta-thalassemia patients?

Transient elastography is the most accurate non-invasive test for assessing advanced liver fibrosis in beta-thalassemia patients.

In patients with beta-thalassemia the evaluation of LIC by MR Imaging has replaced iron concentration in $\mathrm{mg} / \mathrm{g}$ of dry liver on liver biopsy. In parallel, formerly invasive diagnosis of liver damage can be now performed noninvasively evaluating liver stiffness by transient elastography (TE). In not beta-thalassemia patients, TE is the most accurate non-invasive assay in excluding cirrhosis (AUROC 0.90) [43]. The AUROC for fibrosis comparable to a histological stage $\geq 2$ is $0.86[44,45]$.

In patients with beta-thalassemia, this method was evaluated in 4 studies. The first is a controlled cohort study including 56 patients who underwent both liver histology and TE. Results showed that TE is able to discriminate between advanced fibrosis and liver cirrhosis and that the presence of iron overload is not a confounder [45].

A second study was "cross sectional" and included 115 patients with TM or TI. However, only in 14 of them a direct comparison between TE and liver histology was possible [46]. In patients with positive HCV RNA and ferritin levels $>1000 \mathrm{ng} / \mathrm{ml}$, TE overestimated liver fibrosis.

The third study based on 15 patients who underwent both liver biopsy and TE, demonstrated that TE is accurate in assessing the presence of significant fibrosis in patients with beta-thalassemia, showing a sensitivity of $60 \%$ and a specificity of $89 \%$. However, the highest accuracy was attained in diagnosis of cirrhosis with a sensitivity of $100 \%$ and a specificity of $92 \%$ [47]. The fourth study on 49 patients without $\mathrm{HCV}$ infection who underwent $\mathrm{T} 2 * \mathrm{MR}$ and TE showed a significant direct correlation between iron accumulation and liver stiffness [48]. In conclusions, in the absence of an active $\mathrm{HCV}$ infection, TE is as accurate in determining advanced fibrosis status as in patients without beta-thalassemia.

\section{Is the recall policy for early detection of HCC in beta- thalassemia patients different from that used in non beta- thalassemia ones?}

In beta-thalassemia patients, surveillance for early detection of HCC should be based on abdominal US and serum AFP determination every 6 months and on periodic MRI performed according to baseline LIC.

In beta-thalassemia patients, surveillance is needed either to determine iron accumulation into the liver, or to early detect possible HCC growth.

Measurement of iron concentration in liver biopsy (LIC), representative of total body iron stores, has been replaced by MRI LIC assessment [49].

The current surveillance program suggested for betathalassemia patients [50], is stratified according to NTDT or TDT condition and baseline LIC. Both NTDT and TDT patients must undergo biannual MRI if baseline LIC is $>15 \mathrm{mg} / \mathrm{g}$. If baseline LIC ranges between 5 and $15 \mathrm{mg} / \mathrm{g}$ (NTDT), and between 3 and $15 \mathrm{mg} / \mathrm{g}$ (TDT), MRI must be performed annually.

When baseline LIC is $<5 \mathrm{mg} / \mathrm{g}$ (NTDT) or $3 \mathrm{mg} / \mathrm{g}$ (TDT), MRI is advised every 2 years.

Optimal frequency for HCC surveillance is every 6 months (semi-annual). The observed improvement of overall survival in a large Italian cohort [17] is also owed to the wider use of semi-annual surveillance, expanding the proportion of HCC susceptible of curative treatments. Another study in the same cohort [51, 52], had previously demonstrated that semi-annual US 
surveillance has a positive factual benefit in a long-term perspective, not due to lead-time bias, compared to annual one.

Also in beta-thalassemia patients at risk of HCC, surveillance should be performed by abdominal US and AFP serum determination every 6 moths [33, 53]. As for viral infection monitoring, patients undergoing blood transfusion should be tested for $\mathrm{HCV}$ Abs and $\mathrm{HBsAg}$ every year.

\section{AFP}

Although AFP is increased $>400 \mathrm{ng} / \mathrm{ml}$ (the value considered diagnostic for HCC) in only $20-25 \%$ of patients with $\mathrm{HCC}$, either with beta-thalassemia [1, 33] or without [54, 55], it allows to identify patients at risk when baseline values are $>20 \mathrm{ng} / \mathrm{ml}$, or if they increase over time [56]. Increased AFP is associated with an unfavorable outcome [57]. When increased at baseline, it is of great value in monitoring patient treatment response $[57,58]$.

\section{Ultrasound}

US surveillance is essential in detecting small lesions susceptible of curative treatment [17, 51]. For surveillance of HCC in patients without betathalassemia, US has an excellent specificity (90\%) and a sensitivity ranging from 58 to $89 \%$, so often allowing a curative treatment $[17,59]$.

US sensitivity in the diagnosis of early $(<2 \mathrm{~cm}) \mathrm{HCC}$ is not higher than $63 \%$, being such a technique dependent on both operator experience [60] and equipment quality [61]. Limitations to optimal performance of US scanning are obesity, meteorism, presence of coarse-echo-texture in cirrhotics, and low level of patient's compliance.

There are no studies available on the efficacy of US surveillance programs in beta-thalassemia patients, but there are no reasons to hypothesize differences in diagnostic accuracy as compared to non beta-thalassemia patients.

\section{MRI}

In patients affected by beta-thalassemia, MRI with hepatobiliary contrast agent is the best imaging method for confirming the diagnosis of HCC. This because MRI is also sensitive to the presence of iron within tissues and allows quantification of iron overload in the liver. MRI must be performed routinely in beta-thalassemia patients beyond the specific context of HCC surveillance, since it is essential to determine the entity of iron overload in the liver.

A quantification of LIC is necessary to establish the risk of $\mathrm{HCC}$ and the frequency of surveillance. Using MRI, the precise quantification of the iron overload can be performed by two complementary methods validated in the literature. The liver to muscle ratio or SIR (signal intensity ratio); and the calculation of $\mathrm{T} 2 *$ or $\mathrm{R} 2 *(=1 /$ T2*) and its conversion to LIC. Both methods have advantages and disadvantages. Fortunately, there are free software that combine both methods allowing a more precise iron quantification. The MRQuantif software takes into consideration the various $\mathrm{T}_{2}$ * values, the quality of the fit of the curve with the points for each $\mathrm{T} 2 \%$, the steatosis quantification and the SIR result to determine the optimal T2*.

Should MRI not be available, serum ferritin level may be used as a surrogate in TDT patients, being simpler and cheaper than MRI. In NTDT patients, serum ferritin level may underestimate liver iron overload, since increased iron absorption characterizing such condition leads to intracellular storage, with lower levels of serum ferritin.

Regarding HCC diagnosis, after a suspicion of HCC raised by US surveillance, a confirmation imaging technique must be performed. According to the most recently published EASL Guidelines on Management of HCC, CT or MRI should be used at this purpose because of their higher sensitivity. Three meta-analysis $[62,63]$ underlined the superior value of MRI over CT, especially in small lesions and if a hepato-specific contrast medium was used. CEUS should be considered a potential alternative, but lacking strong evidence it cannot be recommended. In comparison to CT or MRI, CEUS sensitivity is significantly lower, especially in nodules of 10 to $20 \mathrm{~mm}$, because of a lower detection rate of washout [63, 64].

None of the previously cited diagnostic procedures is contraindicated in beta-thalassemia patients.

Apart from the usual differential diagnoses, in betathalassemia patients extramedullary hematopoiesis $(\mathrm{EMH})$, a relatively frequent feature in inefficiently transfused patients with TM and much more in patients with TI, should be differentiated from hypovascular HCC. In these cases characterization might require biopsy. EMH may occur in different sites of the body with the most frequent being paravertebral areas, liver, spleen and lymph nodes [65]. Liver involvement is usually diffuse, resulting in hepatomegaly. Focal masses within the liver are much less common, and only around ten of such cases have been reported from 1980 to 2000 [66]. These mass-like foci of EMH need to be distinguished from neoplasms.

On imaging, EMH lesions are well demarcated and usually appear hypoechoic on ultrasound and hypodense on CT, whereas they are hypointense in $\mathrm{T} 1$ and hyperintense in T2 on MRI [67].

Although these lesions do not present typical imaging features of $\mathrm{HCC}$, they might create difficulties in differential diagnosis with hypovascular HCC. So, usually 
these tumor-like lesions require image-guided biopsy for definitive diagnosis [67].

Is the management of early HCC the same in betathalassemia and non beta-thalassemia patients?

A multidisciplinary approach to individualize treatment of early HCC in beta-thalassemia patients should be used.

According to the current guidelines on HCC diagnosis and treatment [68], "early HCC" is defined into two different stages ("very early", or stage 0 , and "early", or stage A) according to liver function, performance status (ECOG-PS), and tumor burden (Table 1).

Subject to liver function preserved (Child-Pugh score A), and ECOG-PS 0 in both groups, "very early stage" is defined when the tumor burden is represented by a solitary nodule $\leq 2 \mathrm{~cm}$ in diameter, and "early stage" when a solitary nodule is $>2 \mathrm{~cm}$ in diameter or up to 3 nodules are all $\leq 3 \mathrm{~cm}$ in diameter.

Though Asian [70], American [71], and European [68] guidelines still recommend ablation only in patients with stage 0 and $\mathrm{A}$ who are not candidates for resection, such technique is now widely considered the first option in solitary tumors $\leq 2 \mathrm{~cm}$ in diameter favorably located within the liver. The most used method is US-guided percutaneous radiofrequency ablation, which causes tumor necrosis by thermal damage [72]. The success rate is inversely related with nodule diameter, so resulting in a worse local control for tumors $>3 \mathrm{~cm}$. However, for nodules up to $3 \mathrm{~cm}$, thermal ablation has been demonstrated equivalent to resection in terms of cumulative recurrence rates and overall survival [73] and is burdened by fewer complications. On the other side, resected patients present higher rates of perioperative mortality and major complications, but also lower rates of local tumor progression [74].

Among ablative therapies, percutaneous ethanol injection (PEI) has been substantially replaced by thermal ablation in the treatment of $\mathrm{HCC}<2 \mathrm{~cm}$ because of its higher rates in cumulative recurrence and local tumor progression, in spite of similar 5-year overall survival [75]. Moreover, the extension of tumoral necrosis produced by PEI is scarcely predictable. Very recently, microwave ablation is achieving a wider role as compared to RF, thanks to its capacity (due to greater usable powers) to obtain similar results in shorter times.

Resection, in stage 0 , is preferred to thermal ablation in selected cases, above all when a laparoscopic approach is feasible, or when the tumor site is not reachable by percutaneous ablative techniques.

In stage A, when the tumor is solitary, resection is the first option regardless of tumor size, above all when there is no clinically significant portal hypertension [76]. If surgical resection is not possible, liver transplantation must be considered.

For beta-thalassemia subjects with early HCC, data available in the literature are scanty, heterogeneous and tailored to individual patients' needs. In an Italian cohort study published in 2014 [1], HCC was already advanced at the time of diagnosis in 21 out of 62 cases (33.9\%), so that only palliative treatment was possible. US surveillance is essential in detecting small lesions susceptible of curative treatment [17].

There are no sufficient data to establish which is the best therapeutic approach in early HCC among thermoablation, liver resection, and liver transplantation. There are no data suggesting that the management of early HCC should be different in patients with or without beta-thalassemia [76]. A multidisciplinary approach involving hematologists, hepatologists, radiologists and oncologists is essential in identifying a tailored treatment [77].

In beta-thalassemia patients with HCC are liver resection indications different from those in patients without betathalassemia?

Surgical treatment of HCC in patients with beta-thalassemia, should follow the same indications applied in non beta-thalassemia patients; because of the higher risk of thromboembolic events during the early postoperative course aggressive coagulation prophylaxis should be adopted.

In latest years, only a few studies have evaluated the surgical treatment of $\mathrm{HCC}$ in patients with betathalassemia [77, 78].

Beta-thalassemia patients with HCC present relevant co-morbidities: hypogonadism (55\%), myocardiopathy (52\%), hypothyroidism (42\%), osteoporosis (31\%), diabetes (31\%) and chronic renal failure (4\%) [79]. This needs to be taken into account when planning surgical resection.

In the largest available study [1] the same therapies currently adopted in non thalassemia patients, either loco-regional, or resective, or chemotherapeutic, or palliative were adopted for beta-thalassemia patients. Such approach, even when aggressive as liver resection, led to a survival improvement in beta-thalassemia patients with HCC (median of 11.5 months) as compared to 2004 (3.5 months median time from diagnosis to death) [1].

Both Maakaron [34], who described a recurrent HCC treated by liver lobectomy after percutaneous thermal ablation, and Moukhadder [35] stated that both surgical and loco-regional ablative therapies should be considered for the treatment of HCC in beta-thalassemia patients. They appear to be safe and effective options $[1,16,77]$. 
Table 1 Stage classification of patients with HCC

\begin{tabular}{|c|c|c|c|c|c|}
\hline Stage & $\begin{array}{l}\text { Very Early Stage } \\
0\end{array}$ & $\begin{array}{l}\text { Early Stage } \\
\text { A }\end{array}$ & $\begin{array}{l}\text { Intermediate Stage } \\
B\end{array}$ & $\begin{array}{l}\text { Advanced } \\
\text { Stage } \\
C\end{array}$ & $\begin{array}{l}\text { Terminal Stage } \\
D\end{array}$ \\
\hline Liver Function & + & + & + & + & - \\
\hline $\begin{array}{l}\text { Performance } \\
\text { Status }\end{array}$ & $\begin{array}{l}\text { ECOG-PS } \\
0\end{array}$ & $\begin{array}{l}\text { ECOG-PS } \\
0\end{array}$ & $\begin{array}{l}\text { ECOG-PS } \\
0\end{array}$ & $\begin{array}{l}\text { ECOG-PS } \\
1-2\end{array}$ & $\begin{array}{l}\text { ECOG-PS } \\
1-2\end{array}$ \\
\hline Tumor Burden & $\begin{array}{l}\text { Solitary } \\
\text { nodule } \leq 2 \mathrm{~cm}\end{array}$ & $\begin{array}{l}\text { Solitary nodule } \leq \\
2 \mathrm{~cm} \text {. } \\
2-3 \text { nodules all }< \\
3 \mathrm{~cm}\end{array}$ & $\begin{array}{l}\text { Multinodular ( }>3 \text { nodules, or } \geq 2 \text { nodules } \\
\text { if any }>3 \mathrm{~cm} \text { ) }\end{array}$ & $\begin{array}{l}\text { Macrovascular invasion or } \\
\text { extraepatic spread }\end{array}$ & $\begin{array}{l}\text { Non- } \\
\text { transplantable } \\
\text { HCC }\end{array}$ \\
\hline
\end{tabular}

ECOG-PS (esternal cooperative oncology group performance status) [69]

The adoption of a more invasive treatment, albeit potentially radical as surgical resection, is also supported by the scarce availability of relevant alternatives. Obviously, an extensive evaluation of potential comorbidities is strongly suggested in the preoperative workup.

Even though there might be no need for specific cardiologic evaluations, it is advised to perform, in patients undergoing surgery, an extremely accurate workout for pulmonary hypertension $(\mathrm{PH})$ that seems more common in adult patients with TI not or inefficiently transfused. Indeed, it is well shown how precapillary $\mathrm{PH}$ may be a devastating complication in beta-thalassemia [80]. An echocardiogram and an echostress test may be suggested in all patients in order to exclude subclinical heart failure (HF) [81].

Pulmonary atelectasia has been frequently described in the setting of beta-thalassemia patients undergoing splenectomy. A preoperative spirometry may be indicated in patients with other risk factors for postoperative ventilatory dysfunction [80].

Present evidence on the best surgical approach between laparotomy and laparoscopy in the setting of HCC are currently limited. However, studies have been published in the particular setting of splenectomy in beta-thalassemia patients [81, 82]. A single randomized study comparing laparotomic vs. laparoscopic splenectomy showed an increased incidence of intraoperative and postoperative bleedings in the laparoscopic group [83]. The results, however, did not reach statistically significant difference [83].

On the other hand, in the HCC general population, laparoscopic approach has been found to be significantly beneficial in terms of postoperative morbidity, mortality, length of hospital stay and blood transfusion requirement when compared to the open approach [81]. On these bases, we suggest that HCC surgical approach in beta-thalassemia patients should be adopted in tertiary surgical centers with high volume of both open and laparoscopic procedures where the laparoscopic choice can be considered in every case and adopted safely.
As far as the postoperative course is concerned, it has to be underlined that thrombotic risk is increased in betathalassemia patients. Few recent evidence report a higher risk of thromboembolic events in particular during the early postoperative course $[84,85]$. However, no clear evidence supporting thromboembolic prophylaxis different from non thalassemia patients is currently available.

Even though studies specifically conducted in betathalassemia patients undergoing liver resection or transplantation for $\mathrm{HCC}$ are not available to date, close postoperative surveillance and aggressive coagulation prophylaxis should be adopted in these patients.

Based on the limited evidence available, liver transplantation in betathalassemia patients is not associated with higher morbidity or mortality compared to patients who are usually referred to liver transplant. Betathalassemia should not be considered per se as a contraindication to liver transplantation.

\section{In beta-thalassemia patients with HCC is liver transplantation associated with higher perioperative mortality?}

Liver Transplantation (LT) is now considered the treatment of choice in patients with HCC. In the past, mainly due to cardiac co-morbidities [77], LT has long been refused to beta-thalassemia patients with end-stage liver disease or HCC. Beta-thalassemia is not longer considered a contraindication to liver transplant anymore provided that severe $\mathrm{PH}$ and subclinical HF are excluded [86]. Thanks to better chelation therapy and iron overload monitoring [1] leading to improved survival, both liver failure and HCC have become a more commonly reported complication, with significant adverse impact on prognosis and mortality [1].

In the series of nine beta-thalassemia patients with HCCs reported by Restivo Pantalone, four patients died during follow-up due to decompensated cirrhosis. The single patient undergone LT (after thermal ablation and TACE) survived 69 months, compared to a median survival of 25 months for four not transplanted patients. The authors concluded that beta-thalassemia should not be considered a contraindication for either treating HCC or for LT [33]. 
Mancuso described two additional patients undergoing successful LT with satisfactory post-transplantation outcomes, without severe complications after 6 months and 2 years of follow-up, respectively [77].

Borgna-Pignatti described three patients undergoing LT, two of whom died shortly afterwards for reasons unrelated to beta-thalassemia [1]. Therefore, after excluding significant co-morbidities as heart dysfunction and $\mathrm{PH}$, beta-thalassemia should no longer be considered a contraindication to liver transplantation which is, as in non beta-thalassemia patients, a potential therapeutic option conferring better survival $[85,86]$.

As reported, only six patients underwent LT for HCC, but the outcomes were affected by beta-thalassemia complications [33].

As, HCC and liver failure can develop in young betathalassemia patients: in this context, the relevant survival benefit offered by LT compared to the standard alternative treatments (transplant benefit) has to be considered.

Prevalence of HLA antibodies is relevantly increased in TM. Even though a high panel reactive antibody percentage is not a contraindication to transplant, the possibility of antibody mediated events has to be carefully considered in postoperative course. On these bases, a regular evaluation of circulating Donor Specific Anti HLA antibodies (DSA) has to be adopted in betathalassemia patients undergoing LT [87].

\section{In beta-thalassemia patients with cardiac dysfunction associated with iron overload, is a combined heart and liver transplantation an option to be considered?}

In highly selected patients, combined heart-liver transplantation could be considered as a possible therapeutic option.

Current indications for combined heart-liver transplantation (CHLT) include end-stage heart and liver disease of varying etiology, in particular familial amyloid polyneuropathy and heart failure with associated cardiac cirrhosis. Liver iron overload leads progressively to chronic liver damage, and some patients may develop liver cirrhosis associated to heart failure.

To date, only one combined heart and liver transplantation has been reported in the setting of betathalassemia [88]. The patient, with a homozygous betathalassemia, was diagnosed when he was 2 years old and started blood transfusions when he was four. At age 11 he underwent splenectomy in order to maintain adequate level of hemoglobin. He started deferoxamine therapy but with low compliance. At age 17 he began to show signs and symptoms of cardiac failure due to heavy iron deposition, confirmed with MRI. The left ventricular ejection fraction was $21 \%$. Despite patient's improved compliance to the therapy, sign of liver failure started to rise: prolonged prothrombin time, low albumin level, increase in liver enzymes. Eventually, he developed ascites and a liver biopsy showed heavy iron loading and portal fibrosis with cirrhosis. At age 26 he underwent combined cardiac and liver transplantation. Eighteen months after transplantation liver showed only focal iron deposition and mild rejection. At a 2-year follow-up, the patient's hepatic and cardiac functions were normal. The authors concluded that they would consider combined organ transplantation for patients with iron loading and severe cardiac dysfunction associated with histological diagnosis of cirrhosis. This may be the only option for patients with end stage iron -related cardiac and liver disease [88].

\section{Are the therapeutic efficacy and complications of TACE and TARE in beta-thalassemia patients the same as in the non beta-thalassemia patients?}

Despite the lack of specific evidence on the use of TACE or TARE in the treatment of HCC, patients with beta-thalassemia should follow the same clinical indications applied to non beta-thalassemia patients.

Despite the absence of specific studies evaluating TACE in the treatment of $\mathrm{HCC}$ in this specific patient's population, important data can be derived from numerous studies demonstrating efficacy and safety of this procedure in $\mathrm{HCC}$ treatment of non beta-thalassemia patients.

According to the Barcelona clinic Liver Cancer (BCLC) system, the most commonly used staging system for treatment and prognosis of $\mathrm{HCC}$ in Western countries [89], TACE is the only recommended treatment strategy in intermediate stage (BCLC B). However, not all patients benefit from TACE in the same way [90] and such heterogeneity has prompted authors to identify prognostic parameters and different scores enabling patients' stratification.

Bolondi and coworkers [91] proposed a subclassification which identified four sub-stages (B1-B4) of intermediate $\mathrm{HCC}$, incorporating the new concept of joint consideration of the tumor burden according to the "beyond Milan" and the "within up-to-7" criteria together with the Child-Pugh score and PS.

For B1 patients, considering their conserved liver function and limited tumor burden, TACE is suggested as first option. For B2 patients [92], 90Y-radioembolization (TARE) or sorafenib could be considered in cases expected not to respond to, to be poor responders or to have contraindications to conventional TACE. For the substage B3, the option of new treatments tested within clinical trials represents the only therapeutic alternative to sorafenib or TACE. In substage B4 patients who met the up-to-7 criteria, liver transplantation is the best option. In patients without alternative therapeutical options, symptomatic 
treatment to avoid unnecessary suffering from liver damage can be offered [93].

New recent evidence suggest the possibility to successfully and safely combine TACE with sorafenib in non beta-thalassemia patients [94].

Trans-arterial radioembolization (TARE), consisting of selective internal radiation therapy (SIRT), is a wellrecognized therapy in a number of guidelines on clinical management of non-resectable HCC [95]. In patients in intermediate stages and history of prior TACE failure or tumoral macrovascular invasion in the absence of extrahepatic spread, according to ESMO (European Society of Medical Oncology) guidelines, TARE may compete with sorafenib [96].

From a technical point of view, TARE is a catheter-based interventional procedure allowing the emission of $\beta$ radiations at therapeutic levels into the tumor through its feeding arteries. Such ultra-selective approach, as for TACE, is aimed to minimizing the effect on healthy liver parenchyma close to the tumor. The local brachytherapy performed by TARE, conversely to TACE, doesn't result in tumor ischemia due to microvascular embolization [97]. Devices for radioembolization are commercially available in form of implantable glass (Therasphere ${ }^{\circ}$ ) or biocompatible resin-based (SIRSpheres ${ }^{\circ}$ ) radioactive $\left(\right.$ Yttrium $\left.^{90}-\mathrm{Y}^{90}\right)$ spheres [97].

TARE is safe [98], also compared to conventional Sorafenib treatment, and no particular attention should be paid in beta-thalassemia patients. Usually, after the procedure, oral amoxicillin/clavulanic acid (375 mg 3 times per day) and pantoprazole ( $40 \mathrm{mg}$ per day) are administered for 3 days [99]. Discharge from the hospital is decided according to individual patients' clinical status. Clinical and laboratory follow-up is advisable [99].

In recent years, the radial approach has been introduced. This technique guarantees a safe vascular access, especially if compared with the brachial one, and allows patients to spend a more comfortable postoperative period considering the possibility of walking immediately after the procedure. Thanks to a greater efficacy of the hemostasis means, this approach is also advisable in patients with coagulation alterations [99].

Which is the systemic therapy and the level of safety in the treatment of advanced HCC in beta-thalassemia patients?

In case of advanced HCC, first-, second-and later-line therapy or the use of checkpoint Inhibitors should follow the same indications of non betathalassemia patients. In the absence of specific contraindications, the safety profile of approved drugs appears comparable in patients with or without beta-thalassemia.

\section{First line therapy}

Recent progress in the area of systemic therapy for advanced HCC in non beta-thalassemia patients have improved life expectancy (Fig. 1). Sorafenib (400 mg daily) or Lenvatinib (8 $\mathrm{mg}$ daily), are current first line drugs, and provide similar survival benefit in patients with advanced HCC.

The multiple tyrosine kinase inhibitor (TKI) Sorafenib, approved in 2007, based on results from the SHARP trial [100] improved the overall survival (OS) versus placebo (median 10.7 vs. 7.9 months, respectively) in 602 patients with advanced HCC (Child-Pugh A) previously untreated with systemic therapy [101]. The median time to radiologic progression (TTP) was significantly longer with sorafenib (5.5 vs. 2.8 months with placebo). Treatment-related adverse events occurred in $80 \%$ of the patients, diarrhea and hand-foot skin reaction being the most frequent. In case of such adverse events, patients may take advantage of symptomatic medications, although $\mathrm{t}$ treatment discontinuation may be required in some cases. Clinically symptomatic vascular disease (either coronary or peripheral) represent formal contraindication [102].

Based on results from REFLECT trials, levantinib was approved in 2019 [103]. Levantinib is an oral multikinase inhibitor targeting VEGFR1-3 and fibroblast growth factor receptor (FGFR) 1-4; it. was shown non inferior to sorafenib in the above open-label, phase III trial enrolling patients with advanced HCC (with the exclusion of patients with main portal vein or bile duct invasion and $>50 \%$ of liver tumor burden). Levantinib doses need to be adjusted by body weight. Incidence of hand-food skin reaction is lower than that reported with sorafenib, although higher incidence of hypertension, proteinuria and anorexia has been reported. Due to lack of solid evidence, the choice of treatment and the sequence of first-, second-, and later-line treatments for advanced HCC in beta-thalassemia patients remain complicated. Only 3 cases of beta-thalassemia patients treated with first line sorafenib are currently reported, and their treatment outcomes are unclear [1]. No data on lenvatinib treatment are available in beta-thalassemia.

\section{Second- and later-line therapy}

For patients who fail or were not able to tolerate the first-line, second- and later-line treatments are needed. From 2009, most clinical trials for second-line agents failed to show any improvement in outcomes among non beta-thalassemia -prior sorafenib-treated- patients. Second line therapy should not be different in betathalassemia as compared to non beta-thalassemia patients. Safety profile appears also comparable in the absence of specific contraindications, but no data are available in beta-thalassemia settings.

Only recently, 3 new drugs were shown effective. Regorafenib, an oral multikinase inhibitor, based on result from RESORCE trials [104], approved in 2019 for 


\section{Therapeutic sequence in HCC: different scenarios}

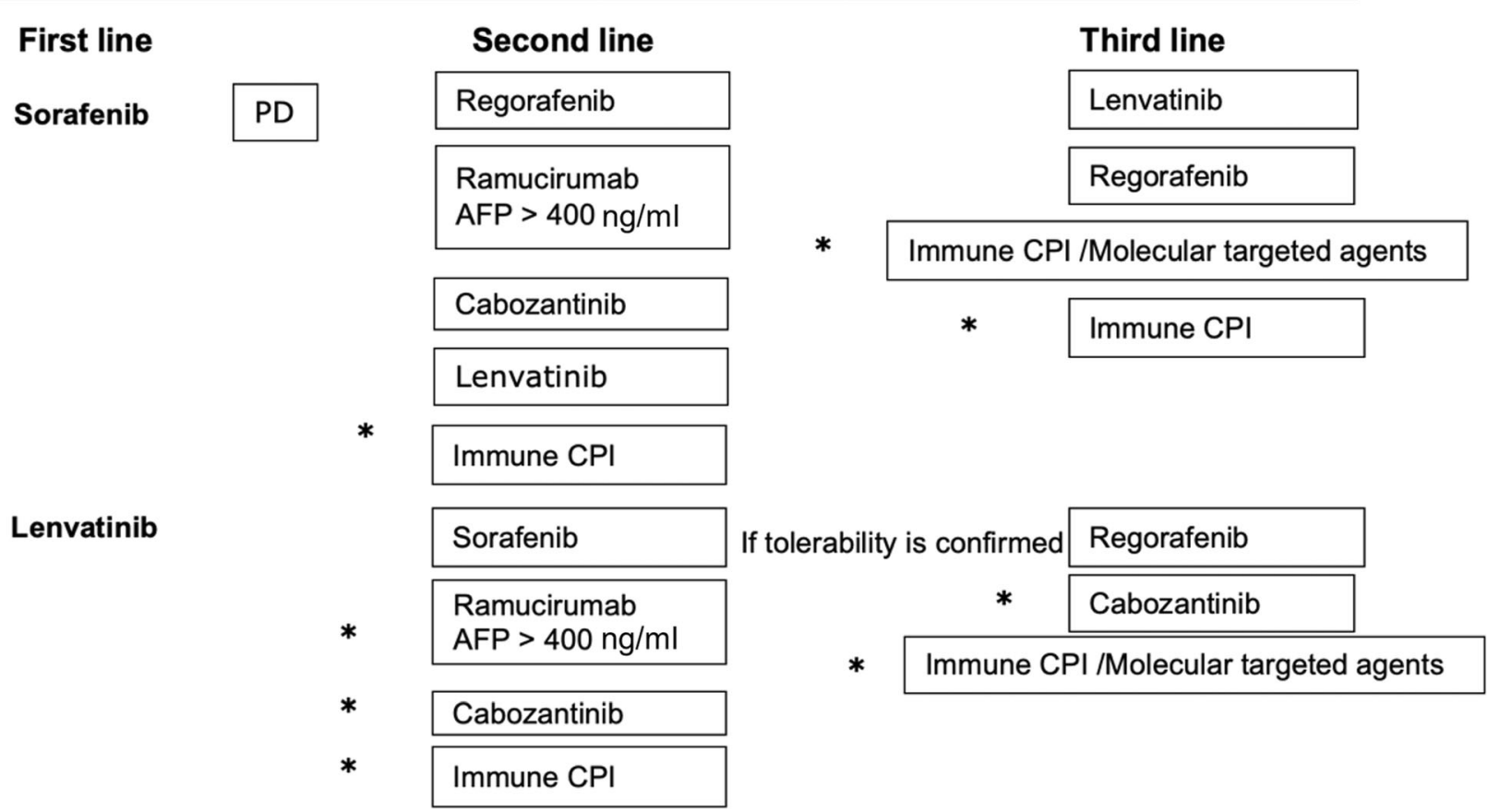

Fig. 1 Therapeutic sequence in HCC: different scenarios. Asterisks indicate that therapeutical sequences are possible but not yet documented in the literature. Use of regorafenib, ramucirumab and cabozantinib or lenvatinib after sorafenib has been proven to be effective. The role of Immune CPI alone or in combination with molecular targeted agents are still under investigations

second line, at dose of $160 \mathrm{mg}$ daily represents the current standard of care for patients with advanced HCC progressing under sorafenib. Regorafenib is recommended in patients with well-preserved liver function and ECOG PS 0-1. The phase III study, comparing regorafenib with placebo in patients with progression despite sorafenib, has reported mean OS 7.8-10.6 months [104]. Treatment improved survival in both BCLC C, and in BCLC B patients. Regorafenib seems to be better tolerated than sorafenib.

For patients in second-line treatment with baseline AFP $\geq 400 \mathrm{ng} / \mathrm{ml}$, well preserved liver function and ECOG PS 0-1, ramucirumab (RAM) can be considered a valid therapeutical option, pending EMA approval [103]. RAM is a human immunoglobulin G1 (IgG1) monoclonal antibody $(\mathrm{mAb})$ that inhibits ligand activation of VEGFR2. In the REACH trial, mean OS in the overall population was not statistically higher. Only the subgroup of patients with AFP $\geq 400 \mathrm{ng} / \mathrm{mL}$ had an improvement. Hypertension and hyponatremia were frequently reported [105].

In patients with progressive disease on one or two systemic therapies, well-preserved liver function and ECOG PS 0-1-pending EMA approval- cabozatinib represents a therapeutic option (Table 1). Phase III CELE STIAL trial [106] evaluated cabozantinib versus placebo in 707 Child-Pugh A patients with HCC progression despite 2 prior systemic regimens. Treatment with cabozantinib resulted in a very limited prolonged OS than placebo (mean OS of 10.2 months with cabozantinib and 8.0 months with placebo). Moreover, the rate of highgrade adverse events in the cabozantinib group was approximately twice that of placebo. In the absence of comparative data between these three agents, ramucirumab may be considered the best choice for patients with AFP $\geq 400 \mathrm{ng} / \mathrm{mL}$ in the event of approval [107]. While well tolerated in the REACH-2 trial, careful monitoring for hypertension, as for cabozantinib and regorafenib, is required.

Definite conclusions cannot be currently drawn [108] and longer follow-up periods will be necessary to understand efficacy and safety of these three new drugs in non beta-thalassemia patients. It is reasonable that betathalassemia patients with HCC should be managed similarly to their non beta-thalassemia counterparts.

\section{Checkpoint inhibitors}

The idea of activating the immune system to target the tumor, rather than directly affecting the cancer cell is not recent. This approach represents a change in therapeutic paradigm, although there are no specific studies performed in patients with beta-thalassemia. The 
PD-1 receptor (Programmed Death 1) is an inhibitory receptor expressed on the surface of $\mathrm{T}$ lymphocytes. Nivolumab is an all-human anti-PD-1 monoclonal antibody capable of inhibiting this immune checkpoint and is currently being studied in a broad clinical development program in different types of cancer, alone or in combination with other therapies [109]. The study with CPI in HCC (Checkmate-459 Nivolumab vs sorafenib) is closed, but unfortunately the expectations were not met.

\section{Is it possible to plan a therapeutic sequence in beta- thalassemia patients with $\mathrm{HCC}$ ?}

In beta-thalassemia patients with HCC, planning a therapeutic sequence may be even more important than in not beta-thalassemia. Due to the high frequency of splenectomy or co-morbidities, a personalized approach by a multidisciplinary group is essential.

Treatment options for HCC in beta-thalassemia patients are largely based on data extrapolated from general population due to the low incidence of HCC in beta-thalassemia. Beside the issue of limited number of beta-thalassemia patients with HCC treated with TKI, the best treatment choice remains controversial. Even more than in other cancers, it is essential that the most appropriate treatment is administered at the right time, considering that suspending therapies might be harmful to the patient. Furthermore, depriving patients of a possible therapeutic alternative available today exposes them to worsening of the liver function that could make an effective alternative treatment no longer feasible.

For these reasons, it is essential that since first diagnosis, beta-thalassemia patients with $\mathrm{HCC}$ are taken over by a multidisciplinary group, following them throughout their therapeutic path [107]. The value of a similar approach is increased in the presence of comorbidities, possible drug interactions (especially hormonal), or metabolic diseases [110]. A number of beta-thalassemia patients has undergone splenectomy and requires medium and long-term prophylaxis protocol with all the scheduled vaccination calls, before starting cancer treatment. Particularly important are Cconjugated or tetravalent anti-meningococcal vaccination and anti-pneumococcal vaccination.

As in non beta-thalassemia patients, a clear therapeutic hierarchy should be adopted in real life in betathalassemia patients as well. It will explore, at first, indication and feasibility of potential radical options as liver resection, ablation or liver transplantation. If radical approaches are not indicated, embolo-therapies represent the second choice followed by first and second line systemic therapies to be adopted according to the multidisciplinary team decision.

\section{Conclusions}

A homogeneous management of HCC in betathalassemia patients is a need for patients and betathalassemia center specialists alike. Despite a gap, due to the paucity of high-quality studies with adequate sample size to determine preferences, there are specific situations -mostly related to the iron overload- that assist in differentiating the diagnostic and therapeutical algorithms in this setting.

\section{Abbreviations}

HCC: Hepatocellular carcinoma; TACE: Trans-arterial chemoembolization; HBV: Hepatitis B virus; HCV: Hepatitis C virus; RMI: Magnetic Resonance Imaging; TARE: Trans-arterial redioembolization; OLT: Orthotopic liver transplantation

\section{Acknowledgements}

The Authors acknowledge Carlotta La Floresta for the professional writing service.

\section{Contributors}

This paper was promoted and supported by Associazione Lotta alla Talassemia ALT "Rino Vullo" Ferrara.

\section{Authors' contributions}

The study was conceived by AM. All Authors (DB, EC, UC, AL, AM, GP, W) contributed to the acquisition of the articles, the analysis of reported data and the writing of the first draft. AM and EC revised the work. All Authors approved the current version of the manuscript.

\section{Funding}

This study was not funded.

Availability of data and materials Not applicable.

Ethics approval and consent to participate

Not applicable.

Consent for publication

Not applicable.

\section{Competing interests}

The Authors declare they have no competing interests.

\section{Author details}

'Liver Unit, Department of Medical Sciences, Fondazione IRCCS "Casa Sollievo della Sofferenza", San Giovanni Rotondo, Italy. ${ }^{2}$ Department of Radiological Sciences, Oncology and Pathology, "SAPIENZA" University of Rome; I.C.O.T. Hospital, Latina, Italy. ${ }^{3}$ Hepatobiliary surgery and Liver Transplant Unit, University of Padua, Padova, Italy. ${ }^{4}$ Department of Surgical Medical Sciences and Translational Medicine, "SAPIENZA" University of Rome; Sant'Andrea University Hospital, Rome, Italy. ${ }^{5}$ Oncology Unit, Oncohematology Department IRCCS, "Casa Sollievo della Sofferenza", San Giovanni Rotondo, Italy. ${ }^{6}$ Diagnostic And Interventional Radiology Department, SM Goretti Hospital, Latina, Italy. ${ }^{7}$ Diagnostic and interventional ultrasound unit, Medical Sciences Department, "Belcolle Hospital", Viterbo, Italy.

Received: 10 March 2020 Accepted: 21 July 2020

Published online: 03 August 2020

\section{References}

1. Borgna-Pignatti C, Vergine C, Lombardo T, Cappellini MD. Hepatocellular carcinoma in thalassaemia: an update of the Italian registry. $\mathrm{Br} J$ Haematol. 2014;167:121-6.

2. Telfer P, Walburton F I, Christou S, et al. Improved survival in thalassemia major patients on switching from desferrioxamine to combined chelation 
therapy with desferrioxamine and deferiprone. Haematologica. 2009;94: $1777-8$.

3. Ladis V, Chouliaras G, Berdoukas V, et al. Survival in a large cohort of Greek patients with transfusion-dependent beta thalassaemia and mortality ratios compared to the general population. Eur J Haematol. 2011;86:332-8.

4. Deugnier Y, Turlin B. Iron and hepatocellular carcinoma. J Gastroenterol Hepatol. 2011;16:491-4.

5. Kowdley KW. Iron, hemochromatosis, and hepatocellular carcinoma. Gastroenterology. 2004;127:S79-86.

6. Fargion S, Valenti L, Fracanzani AL. Hemochromatosis gene (HFE) mutations and cancer risk: expanding the clinical manifestations of hereditary iron overload. Hepatology. 2010;51:1119-21.

7. Cabantchik ZIL. Iron in cells and body fluids: physiology, pathology, and pharmacology. Front Pharmacol. 2014;5(45):1-11.

8. Fargion S, Valenti L, Fracanzani AL. Beyond hereditary hemochromatosis: new insights into the relationship between iron overload and chronic liver diseases. Dig Liver Dis. 2011;43:89-95.

9. Angelucci $E$, et al. Effects of iron overload and hepatitis $C$ virus positivity in determining progression of liver fibrosis in thalassemia following bone marrow transplantation. Blood. 2002;100:17-21.

10. Dwyre DM, Fernando LP, Holland PV. Hepatitis B, hepatitis C and HIV transfusion-transmitted infections in the 21st century. Vox Sang. 2011;100:92-8.

11. Mangia A, et al. Randomised clinical trial: sofosbuvir and ledipasvir in patients with transfusion-dependent thalassaemia and HCV genotype 1 or 4 infection. Aliment Pharmacol Ther. 2017:46:424-31.

12. Associazione Italiana di oncologia Medica. Linee guida Epatocarcinoma 2019 https://www.aiom.it/wp-content/uploads/2019/10/2019_LG_AIOM_ Epatocarcinoma.

13. Kourakli A, et al. Hepatitis C Virus infection, but not hepatic iron overload Is the dominant risk factor for the manifestation of hepatocellular carcinoma among greek thalassemic patientsal. Blood. 2018;132:2347.

14. Di Marco V, et al. Management of chronic viral hepatitis in patients with thalassemia: recommendations from an international panel. Blood. 2010;116: 2875-83.

15. Bray F, et al. Global cancer statistics 2018: GLOBOCAN estimates of incidence and mortality worldwide for 36 cancers in 185 countries. CA Cancer J Clin. 2018;68:394-424.

16. Mancuso A, Sciarrino E, Renda MC, Maggio A. A prospective study of hepatocellular carcinoma incidence in thalassemia. Hemoglobin. 2006;30:119-24.

17. Bucci $L$, et al. The evolutionary scenario of hepatocellular carcinoma in Italy: an update. Liver Int. 2017:37:259-70.

18. Santi $\vee$, et al. Semiannual surveillance is superior to annual surveillance for the detection of early hepatocellular carcinoma and patient survival. J Hepatol. 2010;53:291-7.

19. Prati $D$. Benefits and complications of regular blood transfusion in patients with beta-thalassaemia major. Vox Sang. 2000;79:129-37.

20. Angelucci E, Pilo F. Treatment of hepatitis $C$ in patients with thalassemia Haematologica. 2008:93:1121-3.

21. Di Marco $V$, et al. Liver disease in chelated transfusion-dependent thalassemics: the role of iron overload and chronic hepatitis $C$. Haematologica. 2008;93:1243-6.

22. Mangia A, et al. IL28B CC-genotype association with HLA-DQB $1{ }^{*} 0301$ allele increases the prediction of spontaneous HCV RNA clearance in thalassaemic HCV-infected patients. Antivir Ther. 2011;16:1309-16.

23. Istituto Superiore di Sanità. Malattie trasmissibili con la trasfusione in Italia: sorveglianza epidemiologica dei donatori di sangue. In: Facco G, Piccinini V, Catalano L, Pupella S, Grazzini G, editors. Rapporto 2012, vol. iii; 2014. p. 68. Rapporti ISTISAN 14/4.

24. Prati $D$, et al. Clinical and histological characterization of liver disease in patients with transfusion-dependent beta-thalassemia. A multicenter study of 117 cases. Haematologica. 2004;89:1179-86.

25. Ocak S, Kaya H, Cetin M, et al. Seroprevalence of hepatitis B and hepatitis C in patients with thalassemia and sickle cell anemia in a long-term follow-up. Arch Med Res. 2006;37:895-8.

26. Mansour AK, et al. Prevalence of HBV and HCV infection among multitransfused Egyptian thalassemic patients. Hematol Oncol Stem Cell Ther. 2012;5:54-9.

27. Mandishona $E$, et al. Dietary iron overload as a risk factor for hepatocellular carcinoma in black Africans. Hepatology. 1998;27:1563-6.
28. Finianos A, Matar CF, Taher A. Hepatocellular carcinoma in beta-thalassemia patients: review of the literature with molecular insight into liver carcinogenesis. Int J Mol Sci. 2018;19.

29. Kew MC, et al. Hepatic iron overload and hepatocellular carcinoma. Cancer Lett. 2009;286:38-43

30. Walker EM, Walker SM. Effects of iron overload on the immune system. Ann Clin Lab Sci. 2000;30:354-65.

31. Fattovich G, Stroffolini T, Zagni I, et al. Hepatocellular carcinoma in cirrhosis: incidence and risk factors. Gastroenterology. 2004;127:S35-50.

32. Fragatou S, Tsourveloudis I, Manesis G. Incidence of hepatocellular carcinoma in a thalassemia unit. Hemoglobin. 2010;34:221-6.

33. Restivo Pantalone $\mathrm{G}$, Renda D, et al. Hepatocellular carcinoma in patients with thalassaemia syndromes: clinical characteristics and outcome in a long term single centre experience. Br J Haematol. 2010;150:245-7.

34. Maakaron JE, Cappellini MD, Graziadei G, Ayache JB, et al. Hepatocellular carcinoma in hepatitis-negative patients with thalassemia intermedia: a closer look at the role of siderosis. Ann Hepatol. 2013:12:142-6.

35. Moukhadder HM, Roumi JE, Bou-Fakhredin R, Taher AT. Hepatocellular carcinoma in a beta-thalassemia Intermedia patient: yet another case in the expanding epidemic. Hemoglobin. 2018;42:58-60.

36. Vitrano A, et al. Real-life experience with liver iron concentration R2 MR measurement in patients with hemoglobinopathies: baseline data from LICNET. Eur J Haematol. 2016:97:361-70.

37. Origa $R$, et al. Treatment of hepatitis $C$ virus infection with direct-acting antiviral drugs is safe and effective in patients with hemoglobinopathies. Am J Hematol 2017; 92: 1349-55.

38. Cheung MCM, et al. Outcomes after successful direct-acting antiviral therapy for patients with chronic hepatitis $C$ and decompensated cirrhosis. J Hepatol. 2016;65:741-7.

39. Carrat F, et al. Clinical outcomes in patients with chronic hepatitis $C$ after direct-acting antiviral treatment: a prospective cohort study. Lancet. 2019; 393:1453-64.

40. Calvaruso V, et al. Incidence of Hepatocellular Carcinoma in Patients With HCV-Associated Cirrhosis Treated With Direct-Acting Antiviral Agents. Gastroenterology. 2018;155:411-421.e414.

41. Cho JY, Paik YH, Sohn W, et al. Patients with chronic hepatitis B treated with oral antiviral therapy retain a higher risk for HCC compared with patients with inactive stage disease. Gut. 2014;63:1943-50.

42. Yip TC, et al. Tenofovir Is Associated With Lower Risk of Hepatocellular Carcinoma Than Entecavir in Patients With Chronic HBV Infection in China. Gastroenterology. 2020;158:215-225.e216.

43. Castera L, Pinzani M. Biopsy and non-invasive methods for the diagnosis of liver fibrosis: does it take two to tango? Gut. 2010;59:861-6.

44. Rigamonti C, et al. Transient elastography predicts fibrosis progression in patients with recurrent hepatitis C after liver transplantation. Gut. 2008;57:821-7.

45. Di Marco V, et al. Noninvasive assessment of liver fibrosis in thalassaemia major patients by transient elastography (TE) - lack of interference by iron deposition. Br J Haematol. 2010;148:476-9.

46. Fraquelli $\mathrm{M}$, et al. Transient elastography in the assessment of liver fibrosis in adult thalassemia patients. Am J Hematol. 2010;85:564-8.

47. Mirault T, Lucidarme D, Turlin B, Vandevenne $P$, et al. Non-invasive assessment of liver fibrosis by transient elastography in post transfusional iron overload. Eur J Haematol. 2008;80:337-34044.

48. Siniakos $E$, Perofanis $V$, Vlachaki $E$, et al. Is liver stiffness really unrelated to liver iron concentration ? BrJ Hematol. 2010;150:226-48.

49. Angelucci $\mathrm{E}$, et al. Hepatic iron concentration and total body iron stores in thalassemia major. N Engl J Med. 2000;343:327-31.

50. Taher AT, Cappellini MD. How I manage medical complications of betathalassemia in adults. Blood. 2018:131:1781-91.

51. Del Poggio $P$, et al. Factors that affect efficacy of ultrasound surveillance for early stage hepatocellular carcinoma in patients with cirrhosis, 2014. Clin Gastroenterol Hepatol. 12:1927-1933.e1922.

52. Cucchetti $A$, et al. Estimation of lead-time bias and its impact on the outcome of surveillance for the early diagnosis of hepatocellular carcinoma. J Hepatol. 2014:61:333-41.

53. Giannini EG, Erroi V, Trevisani F. Effectiveness of alpha-fetoprotein for hepatocellular carcinoma surveillance: the return of the living-dead? Expert Rev Gastroenterol Hepatol. 2012;6:441-4.

54. Mancuso A, et al. Hepatocellular carcinoma on cirrhosis-free liver in a HCVinfected thalassemic. Am J Hematol. 2005;78:158-9. 
55. El-Serag HB, Kanwal F. Alpha-fetoprotein in hepatocellular carcinoma surveillance: mend it but do not end it. Clin Gastroenterol Hepatol. 2013;11: 441-3.

56. Lee E, Edward S, Singal AG, Lavieri MS, Volk M. Improving screening for hepatocellular carcinoma by incorporating data on levels of alphafetoprotein, over time. Clin Gastroenterol Hepatol. 2013;11:437-40.

57. Giannini EG, et al. Determinants of alpha-fetoprotein levels in patients with hepatocellular carcinoma: implications for its clinical use. Cancer. 2014;120: 2150-7.

58. Shen YJ, et al. Alpha fetoprotein changes predict hepatocellular carcinoma survival beyond the Milan criteria after hepatectomy. J Surg Res. 2017;209: 102-11.

59. Bolondi, Screening for hepatocellular carcinoma in cirrhosis. J Hepatol. 2003; 39:1076-84.

60. Davila JA, et al. Use of surveillance for hepatocellular carcinoma among patients with cirrhosis in the United States. Hepatology. 2010;52:132-41.

61. Singal A, Volk ML, Waljee A, et al. Meta-analysis: surveillance with ultrasound for early-stage hepatocellular carcinoma in patients with cirrosis. Aliment Pharmacol Ther. 2009;1:37-47.

62. Ye F, Liu J, Ouyang H, et al Gadolinium Ethoxybenzyl Diethylenetriamine Pentaacetic Acid (Gd-EOB-DTPA)-Enhanced Magnetic Resonance Imaging and Multidetector-Row Computed Tomography for the Diagnosis of Hepatocellular Carcinoma: A Systematic Review and Meta-analysis. Medicine 2015; 94: e1157.

63. Duncan JK, Ma N, Vreugdenburg TD, Cameron AL, et al. Gadoxetic acidenhanced MRI for the characterization of hepatocellular carcinoma: a systematic review and meta-analysis. J Magn Reson Imaging. 2017;45:281-90.

64. Lee $\mathrm{YL}$, et al. Hepatocellular carcinoma: diagnostic performance of multidetector CT and MR imaging-a systematic review and meta-analysis. Radiology. 2015;275:97-109.

65. Furlan A, et al. Enhancement pattern of small hepatocellular carcinoma (HCC) at contrast-enhanced US (CEUS), MDCT, and MRI: intermodality agreement and comparison of diagnostic sensitivity between 2005 and 2010 American Association for the Study of Liver Diseases (AASLD) guidelines. Eur J Radiol. 2012;81:2099-105.

66. Leoni $\mathrm{S}$, et al. Characterization of primary and recurrent nodules in liver cirrhosis using contrast-enhanced ultrasound: which vascular criteria should be adopted? Ultraschall Med. 2013;34:280-7.

67. Roberts AS, et al. Extramedullary haematopoiesis: radiological imaging features. Clin Radiol. 2016;71:807-14.

68. EASL Clinical Practice Guidelines. Management of hepatocellular carcinoma. J Hepatol. 2018;69:182-236.

69. Oken MM, Creech RH, Tormey DC, et al. Toxicity and response criteria of the eastern cooperative oncology group. Am J Clin Oncol. 1982;5:649-55.

70. Omata $\mathrm{M}$, et al. Asia-Pacific clinical practice guidelines on the management of hepatocellular carcinoma: a 2017 update. Hepatol Int. 2017;11:317-70.

71. Marrero JA, Ahn J, Rajender Reddy K, et al. Americal college of, ACG clinical guideline: the diagnosis and management of focal liver lesions. Am J Gastroenterol. 2014;109:1328-47.

72. Rossi S, et al. Percutaneous RF interstitial thermal ablation in the treatment of hepatic cancer. AJR Am J Roentgenol. 1996;167:759-68.

73. Forner $\mathrm{A}$, et al. Diagnosis of hepatic nodules $20 \mathrm{~mm}$ or smaller in cirrhosis: prospective validation of the noninvasive diagnostic criteria for hepatocellular carcinoma. Hepatology. 2008;47:97-104.

74. Pompili $\mathrm{M}$, et al. Long-term effectiveness of resection and radiofrequency ablation for single hepatocellular carcinoma $</=3 \mathrm{~cm}$. Results of a multicenter Italian survey. J Hepatol. 2013;59:89-97.

75. Cucchetti A, et al. Cost-effectiveness of hepatic resection versus percutaneous radiofrequency ablation for early hepatocellular carcinoma. J Hepatol. 2013;59:300-7.

76. Pompili $\mathrm{M}$, et al. Single hepatocellular carcinoma smaller than $2 \mathrm{~cm}$ : are ethanol injection and radiofrequency ablation equally effective? Anticance Res. 2015;35:325-32.

77. Mancuso A, Perricone G. Time to define a new strategy for management of hepatocellular carcinoma in thalassaemia? Br J Haematol. 2015;168:304-5.

78. Roayaie $\mathrm{S}$, et al. The role of hepatic resection in the treatment of hepatocellular cancer. Hepatology. 2015;62:440-51.

79. De Sanctis V, Soliman AT, Daar $\mathrm{S}$, et al. A concise review on the frequency, major risk factors and surveillance of hepatocellular carcinoma (HCC) in $\beta$ Thalassemias: past, Present and Future Perspectives and the ICET-A Experience Mediterr. J Hematol Infect Dis. 2020;12:e2020006.
80. Savale L, Habibi A, et al. Clinical phenotypes and outcomes of precapillary pulmonary hypertension of sickle cell disease. Eur Respir J. 2019;54(6). https://doi.org/10.1183/13993003.00585-2019.

81. Gardner K, Suddle A, Kane P, O'Grady J, Heaton N, Bomford A. Thein SLHow we treat sickle hepatopathy and liver transplantation in adults. Blood. 2014; 123:2302-7. https://doi.org/10.1182/blood-2013-12-542076.

82. Sharma A, Easow Mathew M, Puri L. Splenectomy for people with thalassaemia major or intermedia. Cochrane Database Syst Rev. 2019;9: CD010517. https://doi.org/10.1002/14651858.

83. Alexakis $\mathrm{N}$, et al. Incidence, risk factors, and outcome of portal vein thrombosis after laparoscopic-assisted splenectomy in beta-thalassemia patients: a prospective exploratory study. J Laparoendosc Adv Surg Tech. 2013;23:123-8.

84. Xiangfei $M$, Yinzhe $X$, Yingwei $P$, et al. Open versus laparoscopic hepatic resection for hepatocellular carcinoma: a systematic review and metaanalysis. Surg Endosc. 2019:33:2396-418.

85. Wang $\mathrm{M}$, et al. Risk factors of portal vein thrombosis in patients with beta thalassemia major after splenectomy: laparoscopic versus open procedure Hepatogastroenterology. 2014;61:48-54.

86. Gilli SC, et al. Liver transplantation in a patient with (beta)-thalassemia. Transplantation. 2002;74:896-8.

87. Yee ME, et al. Class I and II HLA antibodies in pediatric patients with thalassemia major. Transfusion. 2016;56:878-84.

88. Olivieri NF, et al. Brief report: combined liver and heart transplantation for end-stage iron-induced organ failure in an adult with homozygous betathalassemia. N Engl J Med. 1994;330:1125-7.

89. Forner A, Llovet JM, Bruix J. Hepatocellular carcinoma. Lancet. 2012;379: 1245-55.

90. Piscaglia F, Bolondi L. The intermediate hepatocellular carcinoma stage: should treatment be expanded? Dig Liver Dis. 2010;42:S258-63.

91. Bolondi $L$, et al. Heterogeneity of patients with intermediate (BCLC B) hepatocellular carcinoma: proposal for a subclassification to facilitate treatment decisions. Semin Liver Dis. 2012:32:348-59.

92. Kudo M, et al. Subclassification of BCLC B Stage Hepatocellular Carcinoma and Treatment Strategies: Proposal of Modified Bolondi's Subclassification (Kinki Criteria). Dig Dis. 2015;33:751-8

93. Mazzaferro $\mathrm{V}$, et al. Predicting survival after liver transplantation in patients with hepatocellular carcinoma beyond the Milan criteria: a retrospective, exploratory analysis. Lancet Oncol. 2009:10:35-43.

94. Sangro B, Iñarrairaegui M, Bilbao J. Radioembolization for hepatocellular carcinoma. J Hepatol. 2012:56:464-73.

95. Wu T, et al. Transradial arterial chemoembolization reduces complications and costs in patients with hepatocellular carcinoma. Indian J Cancer. 2015; 52:e107-11.

96. Zou J, Zhu W, Meng H, Luo P, et al. Efficacy and safety of selective internal radiotherapy versus sorafenib for intermediate-locally advanced hepatocellular carcinoma: a systematic review and meta-analysis. Expert Rev Gastroenterol Hepatol. 2019;13:271-9.

97. Kulik L, Vouche M, Koppe S, Lewandowski RJ, Mulcahy MF, Ganger D, Habib A, Karp J, Al-Saden P, Lacouture M, Cotliar J, Abecassis M, Baker T, et al. Prospective randomized pilot study of $Y 90+/-$ Sorafenib as bridge to transplantation in hepatocellular carcinoma. J Hepatol. 2014;61:309-17.

98. Reardon KA, McIntosh AF, Shilling AT, Hagspiel KD, Al-Osaimi A, Berg C, Caldwell SH, Northup PG, Angle F, Mulder R, Rich TA. Treatment of primary liver tumors with Yttrium-90 microspheres (TheraSphere) in high risk patients: analysis of survival and toxicities. Technol Cancer Res Treat. 2009;8:71-7.

99. Liu MD, Uaje MB, Al-Ghazi MS, Fields D, Herman J, Kuo JV, Milne N, Nguyen TH, Ramsinghani NS, Tokita KM, Tsai FY, Vajgrt DJ, Imagawa DK. Use of Yttrium-90 TheraSphere for the treatment of unresectable hepatocellular carcinoma. Am Surg. 2004;70:947-53.

100. Llovet JM, et al. Sorafenib in advanced hepatocellular carcinoma. N Engl J Med. 2008:359:378-90.

101. Bruix J, et al. Prognostic factors and predictors of sorafenib benefit in patients with hepatocellular carcinoma: analysis of two phase III studies. J Hepatol. 2017:67:999-1008.

102. Kudo $M$, et al. Lenvatinib versus sorafenib in first-line treatment of patients with unresectable hepatocellular carcinoma: a randomised phase 3 noninferiority trial. Lancet. 2018;391:1163-73.

103. Zhu AX, et al. Ramucirumab after sorafenib in patients with advanced hepatocellular carcinoma and increased alpha-fetoprotein concentrations (REACH-2): a randomised, double-blind, placebo-controlled, phase 3 trial. Lancet Oncol. 2019;20:282-96. 
104. Bruix J, et al. Regorafenib for patients with hepatocellular carcinoma who progressed on sorafenib treatment (RESORCE): a randomised, double-blind, placebo-controlled, phase 3 trial. Lancet. 2017;389:56-66.

105. Llovet JM, Montal R, Sia D, et al. Molecular therapies and precision medicine for hepatocellular carcinoma. Nat Rev Clin Oncol. 2018;15:599-616.

106. Abou-Alfa GK, et al. Cabozantinib in patients with advanced and progressing hepatocellular carcinoma. N Engl J Med. 2018;379:54-63.

107. Mody K, Abou-Alfa GK, et al. Systemic therapy for advanced hepatocellular carcinoma in an evolving landscape. Curr Treat Options in Oncol. 2019;20:3. https://doi.org/10.1007/s11864-019-0601-1.

108. Mancuso A. Management of hepatocellular carcinoma: enlightening the gray zones. World J Hepatol. 2013;5:302-10.

109. Rimassa L, Pressiani T, Merle P. Systemic treatment options in hepatocellular carcinoma. Liver Cancer. 2019;8:427-46.

110. Raoul JL, Frenel JS, Raimbourg J, et al. Current options and future possibilities for the systemic treatment of hepatocellular carcinoma. Hepat Oncol. 2019;6(1). https://doi.org/10.2217/hep-2019-0001.

\section{Publisher's Note}

Springer Nature remains neutral with regard to jurisdictional claims in published maps and institutional affiliations.

Ready to submit your research? Choose BMC and benefit from:

- fast, convenient online submission

- thorough peer review by experienced researchers in your field

- rapid publication on acceptance

- support for research data, including large and complex data types

- gold Open Access which fosters wider collaboration and increased citations

- maximum visibility for your research: over $100 \mathrm{M}$ website views per year

At $\mathrm{BMC}$, research is always in progress.

Learn more biomedcentral.com/submissions 